\title{
The effects of anchoring and practice on the learning of bidimensional vibrotactile signals
}

\author{
D. D. DIESPECKER ${ }^{1}$ \\ THE UNIVERSITY OF NEWCASTLE, Australia
}

Two groups of $\mathrm{Ss}$ were required to make judgments of bidimensional vibrotactile signals over a period of five weeks (one session per week). Group A Ss were given 54 signals in four matrices ( 2 by 2,3 by 3, 4 by 4, and 5 by 5). Four anchors within the range were also given and were additionally judged among the 54 signals. The size of the A group decreased weekly from 30 to 6 Ss. Delayed knowledge of results (KOR) was given at the end of each session and the same random order of transmitting signals was used in each session. Group B Ss completed an extra (6 by 6) matrix and had one additional anchor, but they received no KOR and the random order of signal transmission was always varied. There was no significant difference between subgroups. Channel capacity was not obtained but the maximum information transmission was 3.08 bits. Practice generally increased $T(x ; y)$ at each session.

Alluisi $(1957,1961)$ has stated that the experimental measuring of channel capacity requires optimal conditions of range, spacing, number of response categories, and knowledge of results. This implies that such conditions would apply regardless of the sense modality being employed, i.e., they would apply to vibrotactile channel capacity. It is difficult to obtain an accurate assessment of vibrotactile channel capacity since the assessment can be made in a number of ways. For example, skin sensitivity varies over the body, and some vibrotactile signals are one-dimensional while others may have several dimensions. The contactor area of vibrators (Verrillo, 1963, 1966) and some of the characteristics of vibrators may also be relevant factors. Many other variables will undoubtedly affect performance when judgments of vibrotactile (and other sensory stimuli) are being made. Some of these are individual differences, air temperature, and whole-body vibration. In experiments made to study absolute judgments, magnitude estimations, or stimulus ratings it is sometimes desirable to present stimuli in practice sessions before beginning an experimental program (Klemmer \& Frick, 1953; Hawkes, 1962; Bliss et al, 1966). Such familiarization with otherwise novel stimuli may have a measurable effect on performance.

If it is accepted that a number of factors and variables do affect the channel capacity of, for example, the skin, it follows that the conditions under which the channel capacity is measured must be carefully specified. The "channel capacity" computed from measurements obtained with the Howell system (Howell, 1956) may be quite different to the "channel capacity" obtained under any other system. Howell's system utilizes five vibrators, three intensities, and three durations. The manipulation of these and perhaps other dimensions in a cutaneous communication system would seem to be critically important. Geldard (1960) has pointed out that the use of derived dimensions would add redundancy. Such addition would be a valuable aid in increasing the efficiency of a vibrotactile communication system.

Feedback, or knowledge of results (KOR), is known to be an important factor when the effects of practice are being measured in judgment-making situations. Ammons (1956) has listed a number of generalizations relevant to KOR. One of these states that (almost universally) where knowledge of their performance is given to one group and knowledge is effectively withheld or decreased in the case of another group, the former group learns more rapidly, and reaches a higher level of proficiency. Ryback (1967) has reported that confidence increased with experience, although accuracy did not, in the absence of feedback; he has also cited studies which show that no learning takes place in the absence of feedback (in a variety of tasks).

The present study was designed to obtain data relevant to vibrotactile channel capacity, and to observe the effects of practice under conditions of minimum feedback.

\begin{abstract}
METHOD
Subjects

Two groups of Ss were run. Members of the first group (Group A) were undergraduate students in psychology classes in the University of Newcastle. There were 30 volunteers in this group for the first session. Of the original 30 , only 19 Ss returned a week later for the second session, 15 Ss returned for the third, 13 Ss for the fourth, and six Ss returned for the fifth session. A second group (Group B) consisted of six Ss, one of whom was a psychology student. Of the remainder, four were housewives who had not previously taken part in a psychological experiment. The sixth member was a 10-year-old girl. Each member of the second group completed five sessions.
\end{abstract}

\section{Apparatus}

Five modified Sherrick-type vibrators (Sherrick, 1965) were used to transmit signals of varying intensity and duration through the skin of Ss. The modifications have been described elsewhere (Diespecker, 1967b). Each S received signals through one vibrator. Signals were transmitted to the vibrators via two transformers and a decade interval timer. A $240 \mathrm{~V}-32 \mathrm{~V}$ step-down transformer was used in conjunction with an auto-variable transformer to isolate the domestic mains supply. $(240 \mathrm{~V}, 50 \mathrm{~Hz})$. The apparatus was located in a laboratory fitted with a one-way screen and signals were transmitted by wires to the vibrators in an adjacent laboratory. Exhaust fans in both rooms were used to mask the operation noise of the timer.

\section{Procedure}

Subjects were run in groups since five communication lines were available. Each sat comfortably at a small table and had a single vibrator taped to the volar surface of the left forearm at a point about 2 in. below the elbow joint. The $E$ explained the procedure to Ss, telling them that they would be required to make two-dimensional judgments of vibrotactile signals. Each $S$ was given a graphical representation of each of the signals. This has been reproduced in Fig. 1.

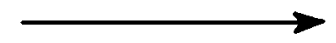

\section{DURATION}

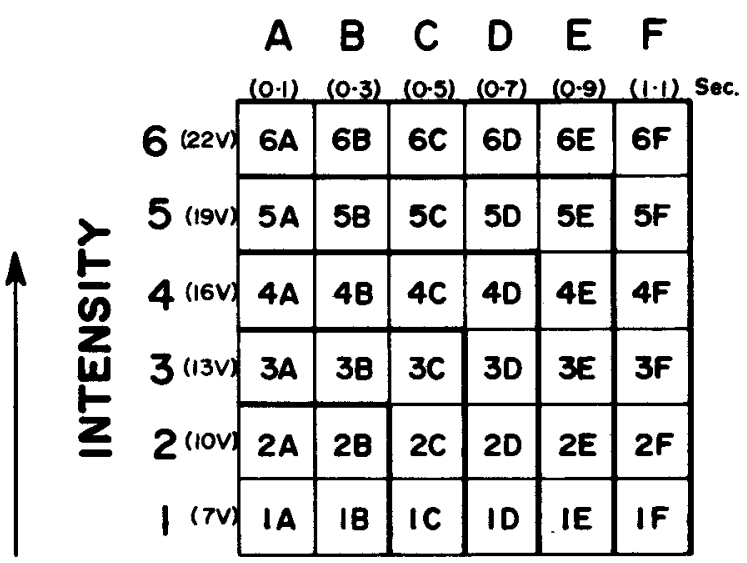

Fig. 1. Graphical representation of signals which were avilable to all Ss throughout the experiment. 
It was not essential for Ss to note the voltages which produced each intensity, nor the durations (in fractions of a sec) which identified the length of each signal, but this information was supplied to add redundancy.

The task of Ss was to complete an answer sheet by noting the identifying numericalalphabetical representation of the signals immediately after each had been transmitted. Each session was divided into four sections (five for Group B). The first section consisted of four signals ( 2 by 2 matrix); the second section, nine signals ( 3 by 3 matrix); the third section, 16 signals ( 4 by 4 matrix); the fourth section, 25 signals ( 5 by 5 matrix); and the fifth section, 36 signals ( 6 by 6 matrix). The Ss were required to complete blank spaces in each section in serial order. Spaces were provided adjacent to numbered lists under each section ("1st " "2nd . . . . "nth___" The E explained that each section or matrix of the program would be marked by a demonstration signal which would be the longest and strongest signal for that particular section. When the instructions were understood, E moved to the apparatus laboratory and gave a visual signal before transmitting the vibratory equivalent of signal 2B to the vibrators. The Ss were not required to note this signal on their answer sheets. The four signals in the 2 by 2 matrix (including the demonstration signal) were then transmitted in random order. The Ss received a visual warning before the onset of each signal since $E$ raised a remote control switch to head height before transmitting the signal. Manipulation of the control apparatus was otherwise shielded from the S's view. All Ss were allowed adequate time to estimate the "size" of each signal, and $E$ did not begin a new signal until all Ss had completed their identifications. When the first section had been completed, a visual signal preceded $3 C$ (the demonstration signal for the 3 by 3 matrix), and this was followed by the nine signals in that matrix. The procedure was followed until each of the four (or five) demonstration signals and the 54 (or 90) test signals had been transmitted.

On completion of the session $E$ returned to the adjoining room to announce the end of transmission. Group A Ss were asked to check their responses against E's list ( $E$ read the correct sequence of signals to Ss). The (random) order of presentation was the same at each session although this information was not given unless requested. The $S s$ were invited to return for additional sessions at one week intervals "if possible." Group B Ss had no KOR, and their answer sheets were not checked in their presence. These Ss were also invited to return at one week intervals. For this group the order of presentation was varied on each occasion. The results of all Group B sessions were communicated to these Ss after the completion of the final session.

\section{RESULTS}

The amount of information transmitted, $T(x ; y)$, was computed for subgroups of Ss after each practice session. A selection of the data has been plotted in Fig. 2. The original number of Group A Ss was 30 and the number decreased after each session. The number of Ss in Group B remained constant, and the six Ss completed five practice sessions. The first two graphs in Fig. 2 indicate the decreasing sizes of the A subgroups.

The results show that information transfer generally increased with practice for both groups of Ss and that the channel capacity was not reached despite an increasingly large number of alternative responses. The distribution of stimuli for the Group A Ss had an uncertainty of 4.64 bits and the maximum $T(x ; y)$ value was 3.03 bits (fifth session, 5 by 5 matrix, six Ss). For the Group B Ss the maximum amount of information available was 5.17 bits, of which 3.08 bits represented the maximum transfer of information (fourth session, 6 by 6 matrix, six Ss). $T(x ; y)$ increased as the size of the A subgroups decreased.

Analyses of variance (Treatments by Subjects design) were applied to the data obtained from the subgroups, i.e., after the second, third, fourth, and fifth training sessions (Lindquist, 1956). $F$ ratios significant at the .01 level were obtained from the second, third, and fourth $A$ subgroups $(F=8.88, \mathrm{df}=1 / 18 ; \mathrm{F}=5.88, \mathrm{df}=$ $2 / 28 ; F=6.44$, df $=3 / 36$ ). The $F$ ratio was not significant for either the six Group A Ss who completed five sessions, or for the six Group B Ss $(F=2.47, \mathrm{df}=4 / 20, \mathrm{p}>.05 ; \mathrm{F}=1.83, \mathrm{df}=4 / 20$, $\mathrm{p}>.05)$.

Some of the Group A data were re-examined to determine whether a sex difference might have contributed to a performance trend. Data from the four matrices of the first session were analyzed by $t$ tests but no significant differences were found $(t=$ $0.32,1.13,0.69,0.89$, df $=28, p>0.05$ ).

Types of errors were studied for each matrix over the five sessions for Group A Ss. Three types of errors were possible: intensity, duration, and combined intensity-duration. In 16 of the 20 matrices (over the five sessions), the lowest proportion of errors (of total responses) was for the intensity dimension. For four of the matrices, duration type errors yielded the lowest proportion. Combined dimensions accounted for the largest proportion of errors. The same trend was found for Group B Ss.

\section{DISCUSSION}

The maximum information transmitted by 30 Ss in the first training session was only 1.37 bits and the slope of the lowest curve in Fig. 2 suggests that the channel capacity for these Ss after only one session would not have greatly exceeded the obtained $T(x ; y)$ figure. Such a value is well below the expected 2-3 bits

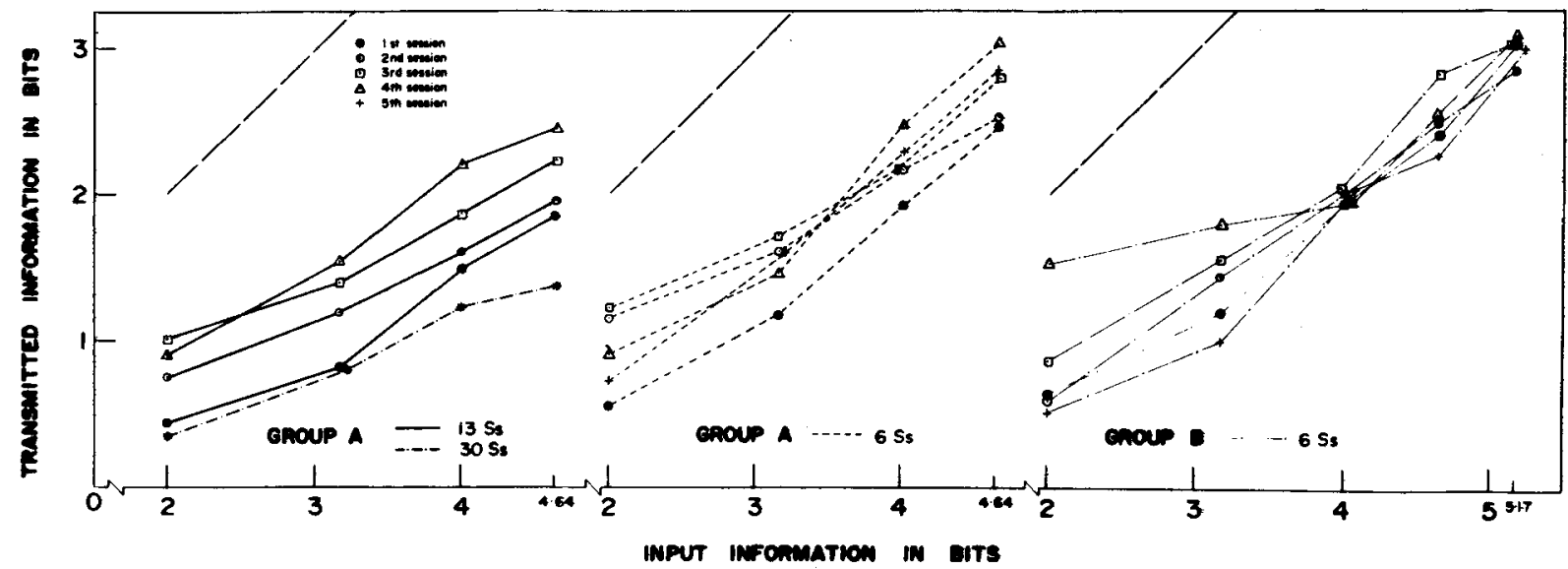

Fig. 2. Selection of performance curves for Group A and Group B Ss. There were 30 Gronp A So in the firat seavion, 19 in the second, 15 in the thind, 13 in the fourth, and six in the fifth sescion. Group B Ss completed five matrices of signals, ef. four matrices for the Group A Ss. 
capacity for unidimensional stimuli reported by Miller (1956). However, the maximum amount of transmitted information increased in second and subsequent sessions without the channel capacity having been reached.

The effect of practice is also seen in Fig. 2. Although the sessions were all one week apart, groups of Ss generally improved their performance. The improvement occurred both with and without KOR. It may be noted that no groups of Ss succeeded in correctly identifying all of the signals in any one matrix but that the Group B Ss came closest to achieving this during the fourth session. When Ss asked for information regarding the order in which signals were transmitted, Group A was told that the order was random but always the same at each session. Subjects in Group B were told that the order was random and that the randomized lists of signals were varied at each session. It might therefore have been expected that the Group A Ss would have learned to correctly discriminate all four signals in the first matrix, especially since they were able to check their responses immediately after every session. The checking of responses at the end of sessions provided delayed feedback which presumably was both rewarding and-despite the weekly decrease in the size of Group A-motivating. KOR does not appear to have contributed significantly to performance, but it may be argued that the regular demonstration of anchor signals in each matrix did aid learning. The problem which each $S$ was faced with was the perception of one of an increasingly greater number of alternative stimuli which varied in two dimensions; but these discriminations were not made as absolute judgments, they were aided by the presentation of anchors. Thus, Ss had available to them a priori matrices of possible signals, a small number of which were always presented as examples during each session. In the terms of Bevan and Pritchard (1963), the anchors appear to have been highly "relevant" because they were included in the range of possible stimuli, i.e., they did not occur outside the range. Adamson (1967) has shown that anchors of $0.05 \mathrm{sec}$ and $1 \mathrm{sec}$ significantly affected the lowering of adaptation level when series stimuli of $2,4,6,8$, and $10 \mathrm{sec}$ were judged.

If vibrotactile channel capacity is to be determined by utilizing a one-vibrator system, then the results of the error analysis in the present study may be of significance. Howell (1956), Geldard (1960), and Diespecker (1967a) have reported that in an analysis of errors in a communication system which codes locus, intensity, and duration, most of the errors will be made along the intensity dimension. The use of only one locus and the coding of intensity and duration in the present study resulted in the intensity dimension being consistently the most stable dimension when errors were made.

The data obtained from the present study show that bidimensional vibrotactile signals can be learned with practice and that anchors within the range of possible stimuli contribute to improved discrimination. The results also suggest that the difference between delayed KOR and no KOR will not be significant in this type of experiment. Although the channel capacity was not reached for any group of Ss, it was in excess of 3.08 bits and the slope of the performance curves suggests that the true value would be close to the channel capacities for multidimensional stimuli reported by Miller (1956). This implies that further experiments having a similar design but with an increased number of alternative responses would be needed. It is also suggested that anchors might usefully be employed in improving the learning of unidimensional vibrotactile signals and that the channel capacity for other sense modalities can be increased with practice or training.

\section{REFERENCES}

ADAMSON, R. Anchor effect limits. Psychon. Sci., 1967, 9, 179-180.

ALLUSI, E. A. Conditions affecting the amount of information in absolute judgments. Psychol Rev., 1957, 64, 97-103.

ALLUISI, E. A. Toward optimizing man's tactile communication. Percept. mot. Skilss, 1961, 12, 235-245.

AMMONS, R. B. Effects of knowledge of performance: a survey and tentative theoretical formulation. J. gen. Psychol, 1956, 54, 279-299.

BEVAN, W., \& PRITCHARD, J. F. The anchor effect and the problem of relevance in the judgment of shape. J. gen. Psychol., 1963, 69, 147-161.

BLISS, J. C., CRANE, H. D., MANSFIELD, PHYLLIS K., \& TOWNSEND, J. T. Information available in brief tactile presentations. Percept. \& Psychophys, 1966, 1, 273-283.

DIESPECKER, D. D. Vibrotactile learning. Psychon. Sci, 1967a, 9, 107-108.

DIESPECKER, D. D., \& DAVENPORT, W. G. The initial effect of noise on a simple vibrotactile learning task. Percept. \& Psychophys, 1967b, 2, 569-571.

GELDARD, F. A. Some neglected possibilities of communication. Science, $1960,131,1583-1588$.

HAWKES, G. R. Predictability of multidimensional absolute identifications from information transmitted with unidimensional stimuli. J. Psychol, $1962,54,309-316$.

HOWELL, W. C. Training on a vibratory communication system. Unpublished Master's Thesis, Univ, of Virginia, 1956.

KLEMMER, E. T., \& FRICK, F. C. Assimilation of information from dot and matrix patterns. J. exp. Psychol, 1953, 45, 15-19.

LINDQUIST, E. F. Design and analysis of experiments in psychology and education. Boston: Houghton Mifflin Co., 1956.

MILLER, G. A. The magical number seven, plus or minus two: some limits on our capacity for processing information, Psychol. Rev, 1956, 63, 81-97.

RYBACK, D. Confidence and accuracy as a function of experience in judgment-making in the absence of systematic feedback. Percept. mot. Skills, 1967, 24, 331-334.

SHERRICK, C. E. Simple electromechanical vibration transducer. Rev. Sci Instrum, 1965, 36, 1893-1894.

VERRILLO, R. T. Effect of contactor area on the vibrotactile threshold. $J$. Acoust. Soc. Amer., 1963, 35, 1962-1966.

VERRILLO, R. T. Taction thresholds for short pulses. Psychon. Sci., 1966, 4, 409-410.

\section{NOTE}

1. Author's address: Department of Psychology, University of Newcastle, New South Wales, Australia.

(Accepted for publication February 26, 1968.) 